\title{
STRUCTURE OF GRAVITY-SENSITIVE SHEATH AND INTERNODAL PULVINI IN GRASS SHOOTS ${ }^{1}$
}

\author{
P. Dayanandan, Frederick V. Hebard ${ }^{2}$, Van D. Baldwin, \\ and Peter B. KaUfman
}

Department of Botany, University of Michigan, Ann Arbor 48109

\begin{abstract}
A B S T R A C T
The location and some morphological, anatomical, and functional aspects of the gravitysensitive pulvini of a selected number of grass shoots are examined. There are two distinct gravity-sensitive regions near the nodal regions of Gramineae. One, the leaf sheath pulvinus, is located at the base of the sheathing leaf bases, and is characteristic of the subfamily Festucoideae. The other, the internodal pulvinus, is located at the base of the internode, a little above the nodal joint. Most members of the Panicoideae possess internodal pulvini, in addition to more or less developed leaf sheath pulvini. Three members of the Oryzoideae examined possess leaf sheath pulvini only, while Phragmites australis (Arundinoideae) possesses both leaf sheath and internodal pulvini. Leaf sheath pulvini of some grasses develop hairs, cork-silica cell pairs or stomatal apparatuses over the epidermis while many others are devoid of any such idioblasts. Both the leaf sheath and internodal pulvini of all grasses examined preferentially exclude, or accumulate very little silica, whereas the regions of the shoot immediately above and below the pulvini in these same grasses accumulate large quantities of silica. Pulvini remain unsilicified or poorly silicified throughout their life and even after several days following geotropic bending. Pulvini are also distinguished from the regions above and below them by the lack of lignin in the bundle cap cells. Lignin is found only in the xylem vascular tissue, and this consists of annular and helical vessel elements only. The bundle cap cells are rich in pectin and are described as collenchymatous. All pulvini possess specialized zones of cells containing starch statoliths. In response to horizontal displacement of the shoots, the lower side of the pulvini grows by cell elongation only. The collenchymatous cells stretch in a manner that results in alternately thin and thick regions of cell wall.
\end{abstract}

THE REGIONS immediately above the nodes of the jointed flowering shoots of grasses respond to gravitational stimulus by bending upwards when the shoots are displaced from the usual vertical position (Arslan and Bennet-Clark, 1960; Maeda, 1958; Bridges and Wilkins, 1973; Dayanandan, Hebard, and Kaufman, 1976). This response plays an important role in many cereal crops that should counter the prostrating effects of lodging. Modifications in the response of this region are also responsible for the prostrate, inclined or erect habits of lawn, turf and forage grasses. In spite of several early and recent studies of the gravitysensitive regions of grass shoots, the structural features of these regions are still poorly under-

\footnotetext{
${ }^{1}$ Received for publication 14 February 1977; revision accepted 7 June 1977.

This work was supported by NSF Grant BMS 7516359. The authors wish to thank the staff of the University of Michigan Matthaei Botanical Gardens for seed supply and growing some plants, Dr. E. Voss for the identification of several specimens, Dr. W. Bigelow and his staff for use of scanning electron microscope facilities, and Mr. David Bay, Miss Anne Deason, and Mrs. $H$. N. Vaughan for their assistance.

${ }^{2}$ Present address: Department of Plant Pathology and Physiology, Virginia Polytechnic Institute and State University, Blacksburg, Virginia 24060.
}

stood (Sachs, 1872; Elfving, 1883-1884; Montemartini, 1900; Lehman, 1906; Brandes and McGuire, 1951; Brown, Pratt, and Mobley 1959; Osborne, 1974).

In a recent paper (Dayanandan et al., 1976), we reported on some of the structural changes that accompany the geotropic response of the sheath pulvinus in Avena sativa and in a few other festucoid grasses. Almost all members of the subfamily Festucoideae (Pooideae), such as barley, oats, rye, and wheat, possess a specialized gravity-sensitive region located at the base of the leaf sheath, immediately above the nodal plexus (Fig. 1). This region is usually designated as the leaf sheath pulvinus, or simply, pulvinus. When a shoot is placed horizontally, that side of the pulvinus which is nearest to the surface of the ground grows, resulting in an upward curvature of the shoot (Fig. 1). This growth results in the elongation of the epidermis, parenchyma, and the collenchymatous cells. A similar response is also elicited by the application of auxin to vertically positioned pulvini. The collenchymatous cells stretch in a novel manner that results in the alternation of thick and thin regions in the originally uniformly thick walls (Fig. 2-4).

Most members of the subfamilies Panicoideae, 


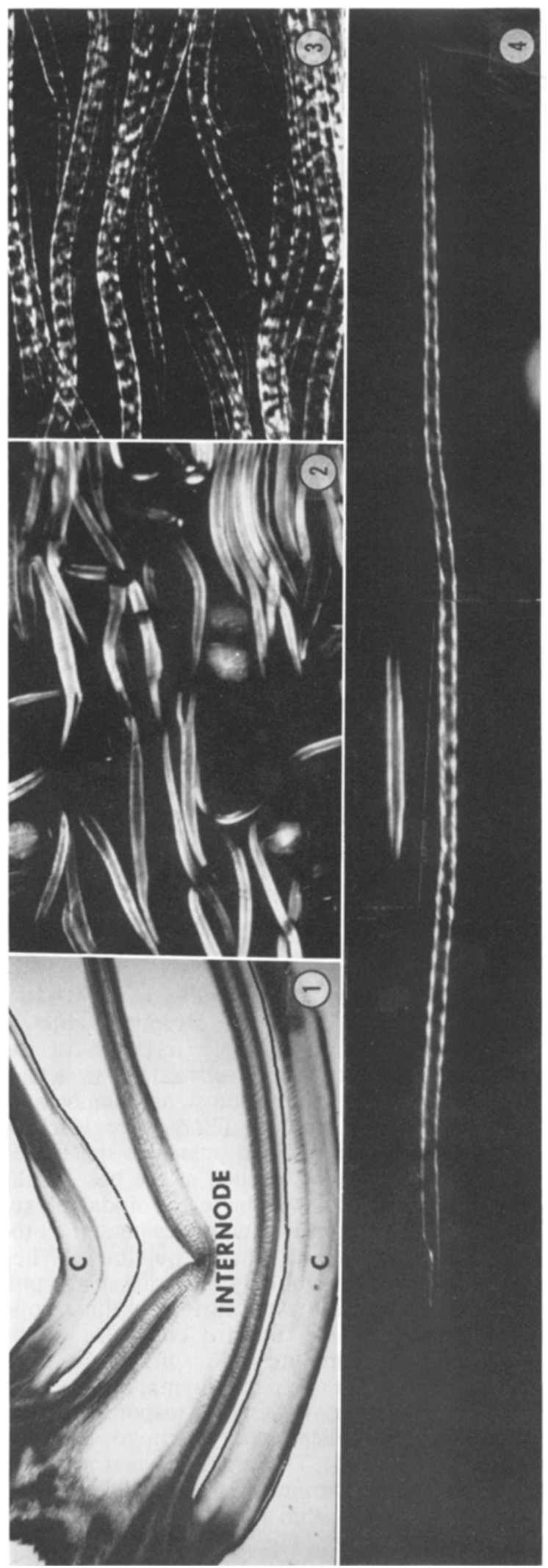

Eragrostoideae, Bambusoideae, and Arundinoideae, on the other hand, possess a gravity-sensitive region at the base of the internode, in addition to the more or less developed sheath pulvinus. Millets, sugarcane, corn, and bamboos belong to this category. Variously described as growth ring (Artschwager, 1940, 1948), culm pulvinus (Brown, Harris, and Graham, 1959), and axial pulvinus (Arber, 1934), the structure of this region in relation to the geotropic response is not well understood. In this report we describe some general morphological and anatomical features of the gravity-sensitive regions located at the bases of the leaf sheaths and internodes of selected grasses.

Although the applicability of the term pulvinus has been questioned (Arslan and Bennet-Clark, 1960 ), we refer to the two gravity-sensitive regions of grass shoots as leaf sheath pulvinus and internodal pulvinus.

MATERIALS AND METHODS-Grass seeds obtained from several sources and maintained at the University of Michigan Matthaei Botanical Gardens were grown outdoors during the summer of 1976. Grasses were also collected from areas around Ann Arbor. These include several species of Panicum, Poa pratensis L., Digitaria sanguinalis (L.) Scop., Phragmites australis (Cav.) Steudel, Echinochloa crusgalli (L.) Beauv., Leersia oryzoides (L.) Swartz, Festuca rubra L., and Agropyron repens (L.) Beauv. Table 1 lists some of the grasses that were examined in detail to locate the gravity-sensitive regions. Not included in this list are several grasses that were examined for one or more of the following features: silicon (Si) distribution on the pulvinus, trichomes on the pulvinus, geotropic response, presence of collen-

$\leftarrow$

Fig. 1-4. Growth response due to geotropic stimulation in Avena sativa. 1. Longitudinal section through the hollow internode and leaf sheath pulvinus of a shoot that had bent during 2 days of geotropic stimulation. The lower side of the pulvinus has elongated while the upper side has contracted. The inner epidermis of the sheath is emphasized by the lines drawn over them. $\mathrm{C}$, collenchymatous bundle cap. $\times 10$. 2. Collenchymatous cells isolated from a control leaf sheath pulvinus and viewed between crossed polarizers. The cells are uniformly birefringent and the walls uniformly thick. $\times 98$. 3. Isolated collenchymatous cells from a leaf sheath pulvinus that had grown in response to $24 \mathrm{~h}$ geotropic stimulation. As seen between crossed polarizers, regions that have stretched appear thin and almost isotropic, whereas the unstretched regions remain as thick and birefringent as in control cells. $\times 98$. 4. Isolated collenchymatous cell from a control leaf sheath pulvinus compared with one derived from a shoot that has been geotropically stimulated for 2 days. Photographed between crossed polarizers. $\times 98$. Figures 2 and 4 are the same as in Dayanandan et al., 1976. 
chymatous cells, and starch statoliths. The grasses examined (not included in Table 1) were: Beckmania sp., Distichlis spicata (L.) Green, Oryza minuta Presl., Saccharum officinarum L., and Muhlenbergia schreberi Gmel.

Morphology and anatomy of the gravity-sensitive regions were studied with light and scanning electron microscopes (SEM). For light microscopy, thin sections were made with razor blades from fresh material and fixed or stained immediately. Macerations were made with $1 \mathrm{~N} \mathrm{HCl}$ at $80 \mathrm{C}$. Fixations, when necessary, were done with FAA. Fresh sections were stained in $\mathrm{I}_{2} \mathrm{KI}$ for the visualization of starch grains, with phloroglucinol- $\mathrm{HCl}$ or pararosanaline- $\mathrm{HCl}$ for staining lignin, with ruthenium red or hydroxylamine-ferric-chloride reagents for staining pectic materials and with chlor-zinc-iodine or $\mathrm{I}_{2} \mathrm{KI}$ followed by $\mathrm{H}_{2} \mathrm{SO}_{4}$ for cellulose (Jensen, 1962). Preparations were examined with a microscope equipped with crossed polarizers and a $1^{\text {st }}$ order Red Plate.

Fresh specimens were used for the study of $\mathrm{Si}$ distribution on the epidermal surfaces. Depending upon the size, entire or sections of the nodal regions were mounted on aluminum stubs with carbon paint and were examined immediately with a SEM (JEOL model JSM-U3). At an accelerating voltage of $15 \mathrm{KeV}$, fresh specimens could be examined for nearly $20 \mathrm{~min}$ without much damage to them. X-ray microanalyses were done by coupling the SEM to an X-ray detector and amplifier system (KEVEX) and a multichannel analyser (Northern Scientific, Model 710). Selected areas were first photographed in the secondary emission mode followed by X-ray mapping for Si.

FAA-fixed material was also dehydrated in an alcohol series and embedded in wax, following conventional procedures. Wax-embedded material was sectioned with a razor blade into 1-2mm pieces and the wax was removed with xylene. Specimens were passed through an alcohol-xylene series to $100 \%$ alcohol and then critical point dried in liquid $\mathrm{CO}_{2}$. Critical point dried material was mounted on aluminum stubs and goldcoated before examination with the SEM.

When the geotropic response of the pulvini was to be studied, sections including this region were placed horizontally on a filter paper saturated with $0.1 \mathrm{M}$ sucrose and were held down on the proximal side so as to facilitate the other, distal end, to bend. Details of these procedures were presented in a previous paper (Dayanandan et al., 1976).

OBSERVATIONS-Location of the gravity-sensitive regions-A region is identified as being gravity-sensitive pulvinus when it possesses the following attributes: (1) a morphologically and anatomically distinctive region that differs from the neighboring regions; (2) the presence of un-
TABLE 1. Species of grasses investigated and the location of gravity-sensitive regions

\begin{tabular}{|c|c|}
\hline Species & $\begin{array}{l}\text { n of gravity- } \\
\text { ve regions }{ }^{a}\end{array}$ \\
\hline FESTUCOIDEAE (POOIDEAE) & \\
\hline $\begin{array}{l}\text { Agropyron repens (L.) Beauv. } \\
\text { Avena fatua } \mathrm{L} . \\
\text { A. sativa } \mathrm{L} . \\
\text { A. strigosa Schreber } \\
\text { Festuca rubra L. } \\
\text { Hordeum distichon } \mathrm{L} . \\
\text { H. jubatum L. } \\
\text { H. vulgare L. } \\
\text { Polypogon monspeliensis (L.) Desf. } \\
\text { Secale cereale } \mathrm{L} \text {. } \\
\text { Triticum aestivum } \mathrm{L} .\end{array}$ & $\begin{array}{l}\text { L } \\
\text { L } \\
\text { L } \\
\text { L } \\
\text { L } \\
\text { L } \\
\text { L } \\
\text { L } \\
\text { L } \\
\text { L } \\
\text { L }\end{array}$ \\
\hline $\begin{array}{l}\text { PANICOIDEAE } \\
\text { Coix lacrima-jobi L. } \\
\text { Digitaria sanguinalis (L.) Scop. } \\
\text { Echinochloa crusgalli (L.) Beauv. } \\
\text { Panicum miliaceum L. } \\
\text { P. capillare L. } \\
\text { Setaria italica L. } \\
\text { Sorghum halepense (L.) Brot. } \\
\text { Zea mays L. }\end{array}$ & 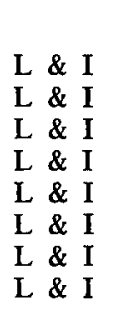 \\
\hline $\begin{array}{l}\text { ARUNDINOIDEAE } \\
\text { Phragmites australis (Cav.) Steudel }\end{array}$ & L \& I \\
\hline $\begin{array}{l}\text { ORYZOIDEAE } \\
\text { Leersia oryzoides (L.) Swartz } \\
\text { Oryza glaberrima Steudel } \\
\text { O. sativa L. }\end{array}$ & $\begin{array}{l}\mathbf{L} \\
\mathbf{L} \\
\mathbf{L}\end{array}$ \\
\hline
\end{tabular}

"L, Leaf sheath pulvinus; I, Internodal pulvinus.

bubfamilies, after Gould (1968).

lignified but pectin-rich collenchymatous cells; (3) the presence of statoliths; (4) the ability to bend in response to gravitational stimulation. Grasses that showed all of these features are listed in Table 1. All 11 festucoid species and three oryzoid species possess only leaf sheath pulvini but no internodal pulvini (Table 1; Fig. 511). Eight members of the Panicoideae and one of Arundinoideae possess internodal pulvini in addition to leaf sheath pulvini (Table 1; Fig. 19, 25, 31). When the leaf sheath of a festucoid member, Avena sativa, is removed so as to exclude the sheath pulvinus and then placed horizontally, the internode base does show a negative geotropic bending response. Some statoliths in this internode base also sediment towards the gravitational field. However, such responses are shown only in young internodes and rapidly disappear with age. Also, the internode in the region that bends does not possess any features that are distinctly different from the general features of the rest of the internode.

Silicon distribution-Distribution of $\mathrm{Si}$ on the outer epidermal surfaces of leaf sheath pulvini 

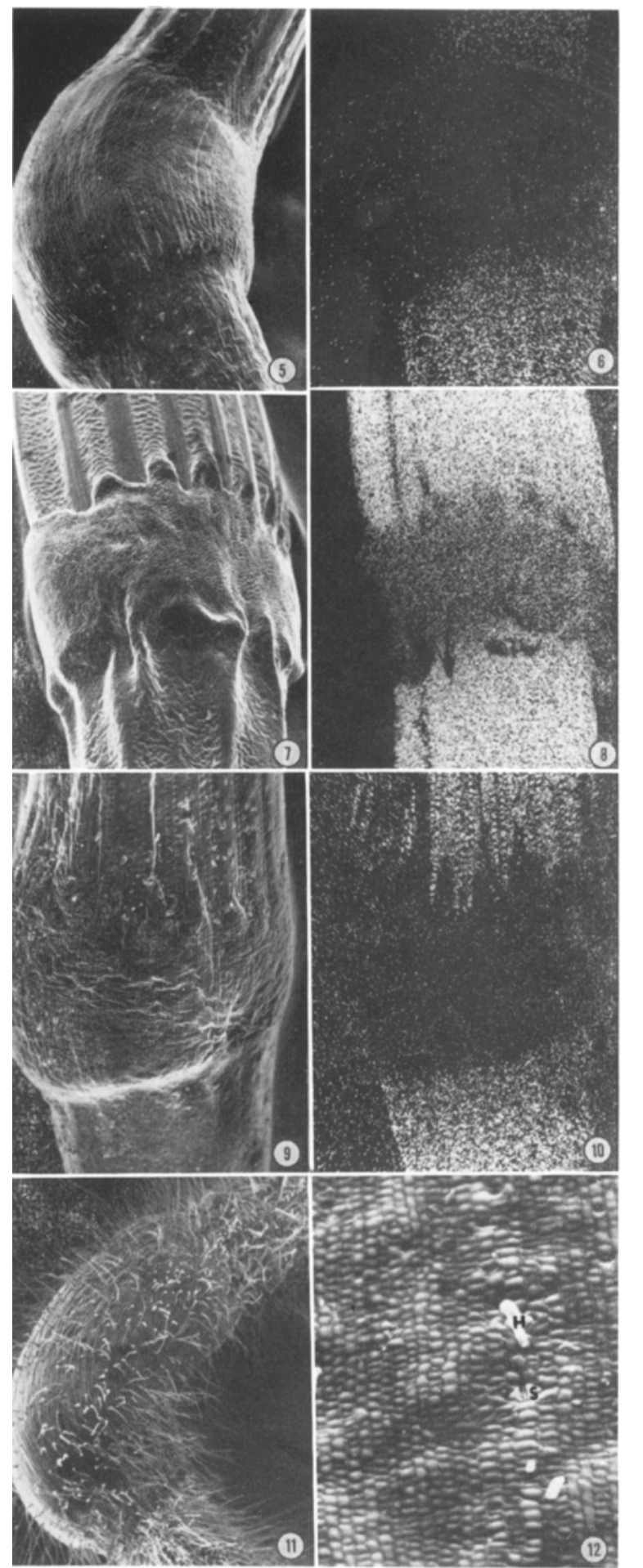

Fig. 5-12. Scanning electron microscope (SEM) views and $\mathrm{X}$-ray mapping for $\mathrm{Si}$ distribution in leaf sheath pulvini in selected grasses. 5, 6. SEM view and Si X-ray map of Festuca rubra. This shoot had undergone natural geotropic stimulation. The regions above and below the pulvinus are highly silicified. The pulvinus itself shows no more than the background distribu- and the regions immediately above and below the pulvini in several grasses are shown in Fig. 5-24. Many grass sheath pulvini possess epidermises that do not have cork-silica cell pairs, trichomes, or stomatal apparatuses (Fig. 5, 9). Barley (Hordeum), oats (Avena), wheat (Triticum), and rice (Oryza) belong to this category. The leaf sheath pulvinus epidermises of these plants accumulate very little $\mathrm{Si}$ when compared with the epidermises of the internode below and the leaf sheath above the pulvini (Fig. 5, 6, 9, 10). Semiquantitative measurements on equal-sized areas reveal that in Avena sativa, there is three-fold greater concentration of $\mathrm{Si}$ on the leaf sheath above the pulvinus and a five-fold greater concentration of $\mathrm{Si}$ on the stem surface immediately below the pulvinus. In barley, the leaf sheath and stem possess three times and seven times greater amounts of $\mathrm{Si}$ as that of the pulvinus. The difference is even greater in wheat-11 times more $\mathrm{Si}$ in the leaf sheath and 13 times more $\mathrm{Si}$ in the stem below the pulvinus. In Setaria italica, there is seven times greater amount of $\mathrm{Si}$ in the leaf sheath above the pulvinus, while the stem surface below the pulvinus possesses 20 times more $\mathrm{Si}$ than the pulvinus. The greater amount of $\mathrm{Si}$ in the epidermis above and below the pulvinus is due to the accumulation of $\mathrm{Si}$ in specialized corksilica cells as well as by the outer tangential and radial walls of the long epidermal cells (Kaufman et al., 1969).

The relative concentrations of $\mathrm{Si}$ in different leaf sheath pulvini, from bottom to top, of a single plant was examined in Avena sativa and Festuca rubra with X-ray microanalysis. In both the plants, there was no significant difference in the amount of $\mathrm{Si}$ in the bottommost pulvini and in the uppermost pulvini. Occasional increased $\mathrm{X}$-ray counts from the bottom pulvini were later found to be due to soil contamination. Similarly, X-ray microanalysis of the pulvini of Avena sativa shoots that have bent in response to gravitystimulation indicated that the bent surfaces show no increase in $\mathrm{Si}$ accumulation even after five days of continuous gravity-stimulation.

Some leaf sheath pulvini possess epidermises

$\leftarrow$

tion of Si. $\times 27.7,8$. Oryza minuta. The leaf sheath pulvinus has numerous silica cells which accumulate Si. Yet, there is less Si here than in the sheath above and in the node below the pulvinus. $\times 27$. 9, 10. Pulvinus and the regions immediately above and below it in Panicum sp. The pulvinus is devoid of idioblasts. Again, the pulvinus has very little Si. $\times 42$. 11. Pulvinus of Polypogon monspeliensis, which is covered with numerous epidermal hairs. The hairs and the rest of the pulvinus accumulate very little Si. $\times 23$. 12. Magnified view of the leaf sheath pulvinus in Zea mays. Stomatal apparatuses (S) and bicellular hairs $(H)$ are seen among short epidermal cells over the pulvinus. $\times 88$. 
that develop hairs, cork-silica cells, or stomatal apparatuses (Fig. 7, 11-24). In Leersia oryzoides, the unicellular hairs present in the leaf sheath pulvinus epidermis accumulate $\mathrm{Si}$ (Fig. 13-16). The ordinary epidermal cells, however, do not accumulate significant quantities of Si (Fig. 13-16). This is also true of a Panicum sp. (Fig. 19, 20) and Phragmites australis. Polypogon monspeliensis and Panicum capillare also develop epidermal hairs on the pulvinus, but these hairs do not accumulate as much $\mathrm{Si}$ as those of $L$. oryzoides (Fig. 11, 21-22). Agropyron repens possesses several $\mathrm{Si}$ cells distributed among nonsilica accumulating, long epidermal cells (Fig. 17, 18). The entire pulvinus, in the case of Oryza minuta, is covered with Si cells (Fig. 7). Yet, these pulvinar silica cells accumulate less Si compared with the cells above and below the pulvinus. Oryza sativa and $O$. glaberrima only possess ordinary, long epidermal cells in the sheath pulvini. The epidermal cells of the leaf sheath pulvinus of Zea mays possess sparsely-distributed rows of stomata and bicellular trichomes (Fig. 12).

The gravity-sensitive region in the internodal base of Phragmites australis also has less $\mathrm{Si}$ over the epidermis compared with the epidermal regions immediately above and below this locus (Fig. 25, 26). In this plant, cork-silica cell pairs occur immediately above the internodal pulvinus (Fig. 27). Some cork-silica cell pairs are also found on the internodal pulvinus but the "silica" cell members are devoid of $\mathrm{Si}$ and the cells appear depressed (Fig. 27, 28). Figures 19 and 20 illustrate a young internode of Panicum sp. and the Si distribution in its epidermis. At this stage, the entire internodal epidermis seems to be devoid of $\mathrm{Si}$; however, in mature internodes, there is $\mathrm{Si}$ accumulation in the hairs above the internodal pulvinus.

The distribution of $\mathrm{Si}$ in the internode of rice (Oryza sativa) was also examined. (Rice does not possess an internodal pulvinus.) The internodes have silica cells distributed among long epidermal cells, hairs, and stomatal apparatuses. The number of silica cells increases towards the base of the internode, until, at the very bottom, silica cells are the only cell type to be found. These silica cells do accumulate Si.

Anatomy of the pulvini-At the bases of the leaf sheaths and internodes, the gravity-sensitive

Fig. 13-20. SEM views and X-ray mapping for $\mathrm{Si}$ in leaf sheath and internodal pulvini in selected grasses. 13, 14. Leersia oryzoides. The leaf sheath pulvinus develops many hairs which accumulate $\mathrm{Si}$. However, the regions above and below the pulvinus have more Si. $\times 22$. 15, 16. Magnified view of leaf sheath pulvinus of $L$. oryzoides. Si is seen to accumulate only in hairs and not in the ordinary epidermal cells between them.
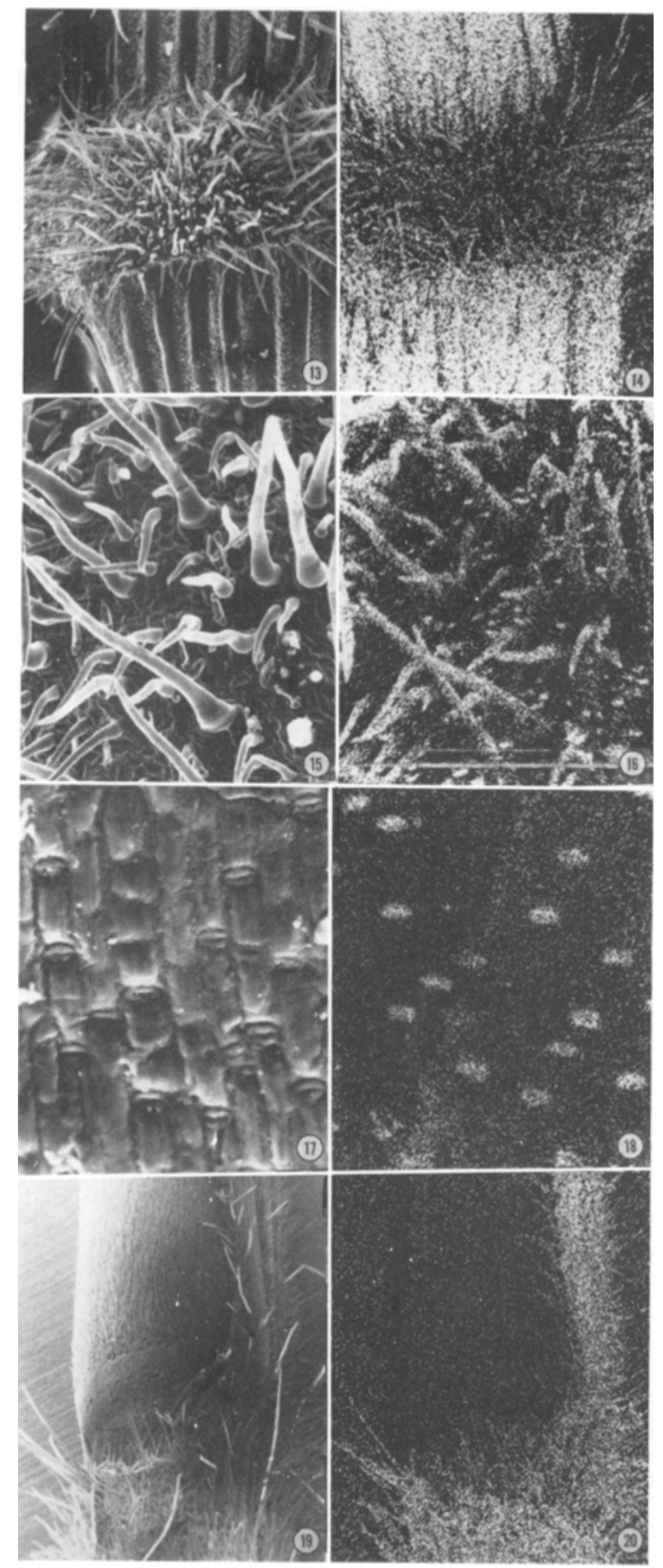

$\times 110$. 17, 18. Leaf sheath pulvinus of Agropyron repens with silica-accumulating cells among silica-poor epidermal cells. $\times 238$. 19, 20. A young shoot of Panicum sp. with leaf sheath partly removed to show the internode. Leaf sheath is covered with hairs that accumulate Si. The sheath pulvinus is not clearly delineated in this view. The internodal pulvinus is free from hairs, whereas the region above it (not shown in this figure) possesses hairs. These hairs accumulate $\mathrm{Si}$ as the segments become older. $\times 22$. 


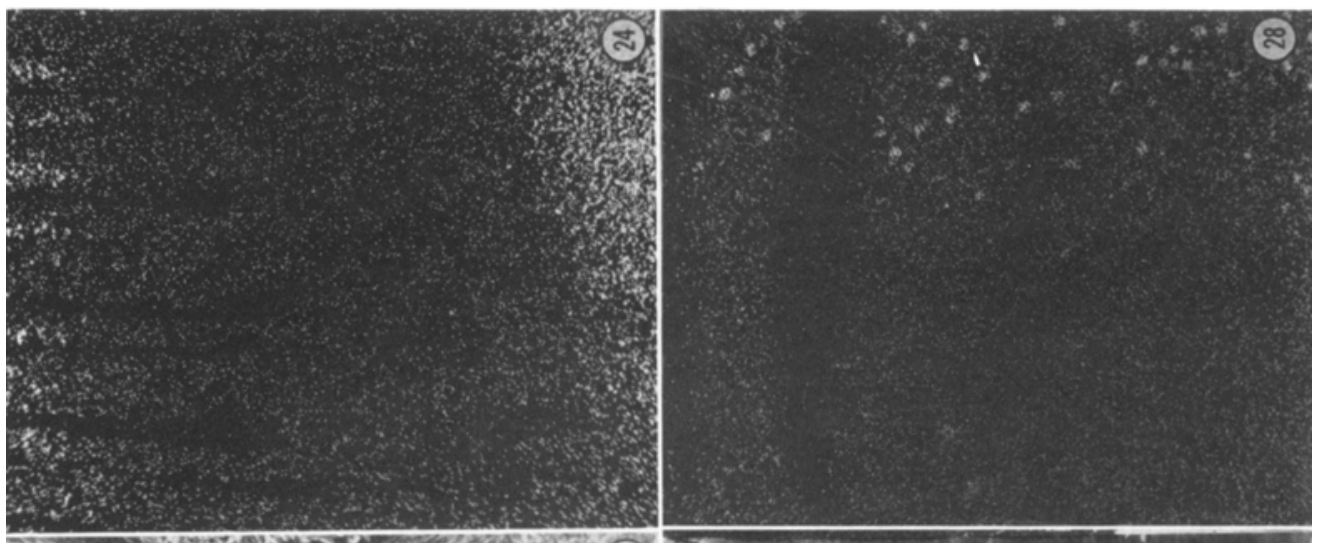

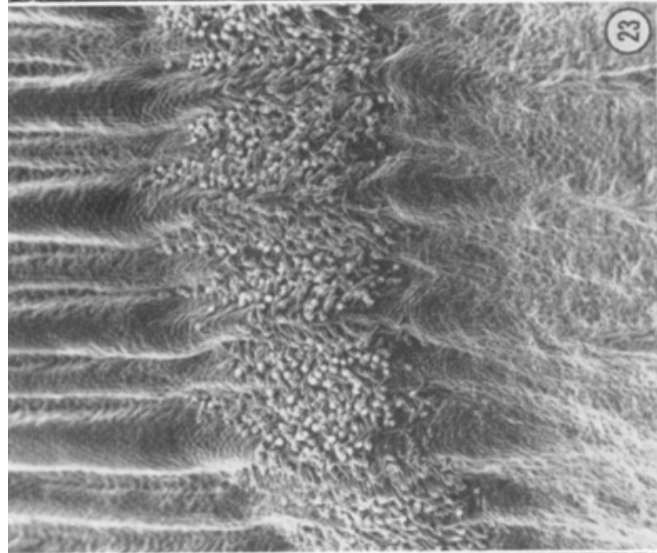
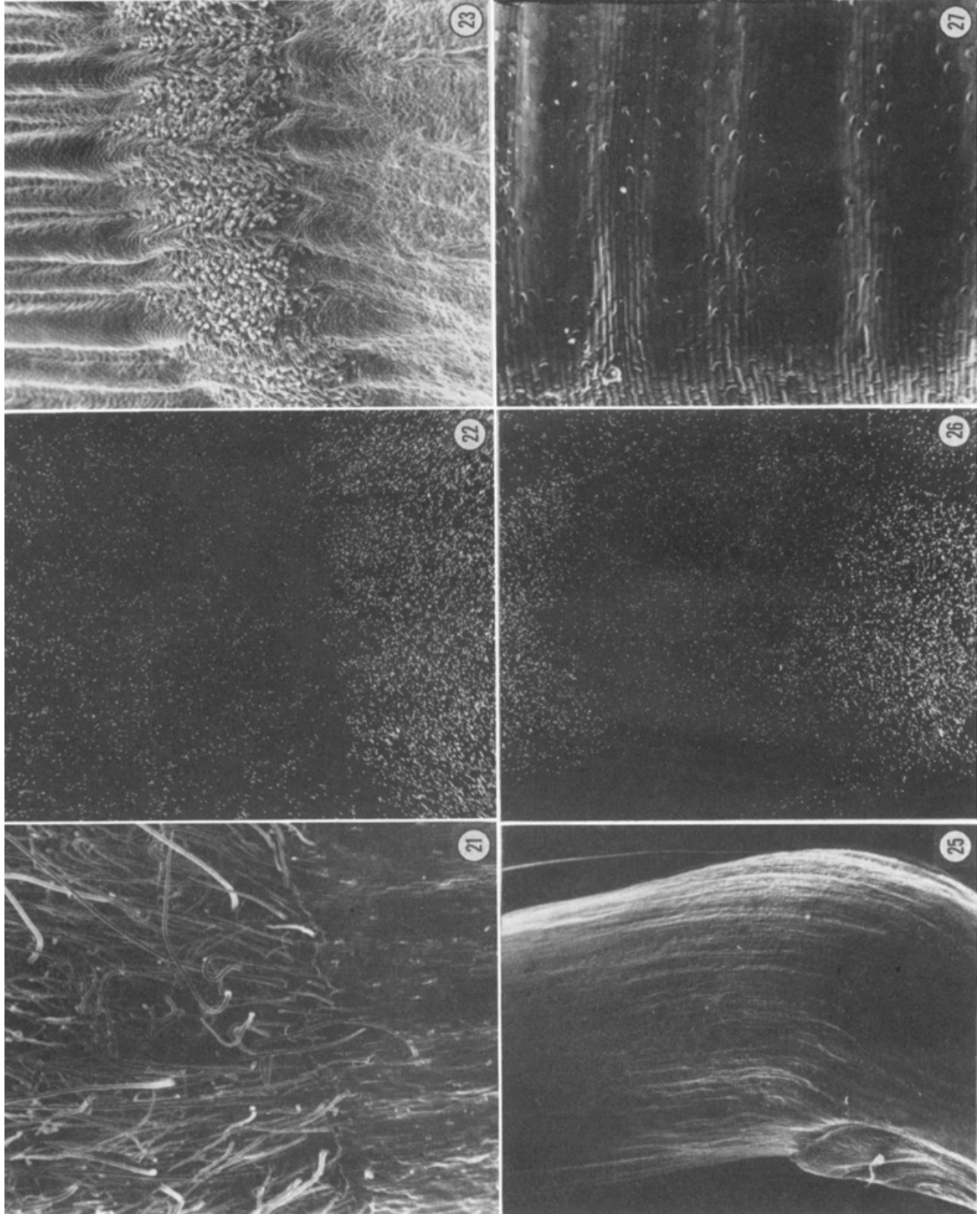

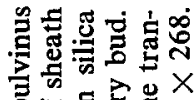

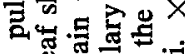

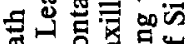
क्ष

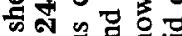

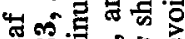
ब

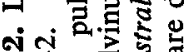
สำ

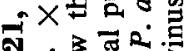
ส

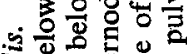
ปั。

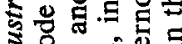
ชิ ४ ․․ 影品 s. 2

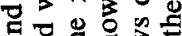
สํ⿺ㄹ 웅 हैं 客 \& \& उo

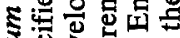

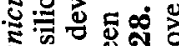
5 क 岁的 太

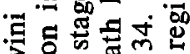
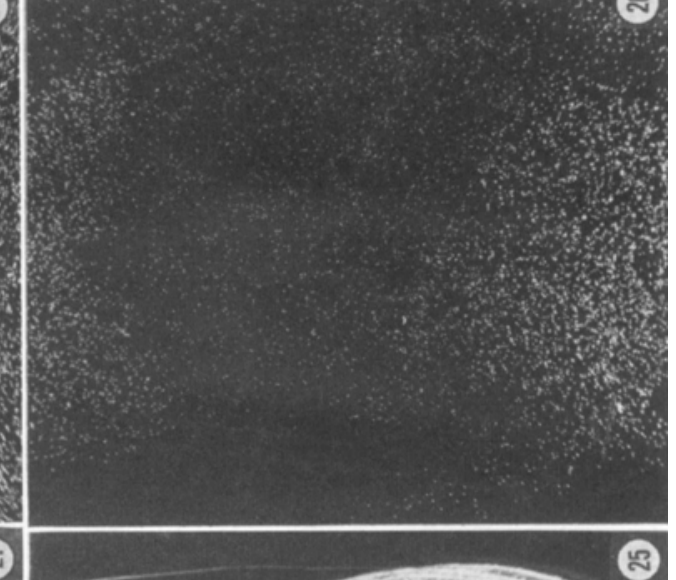

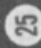

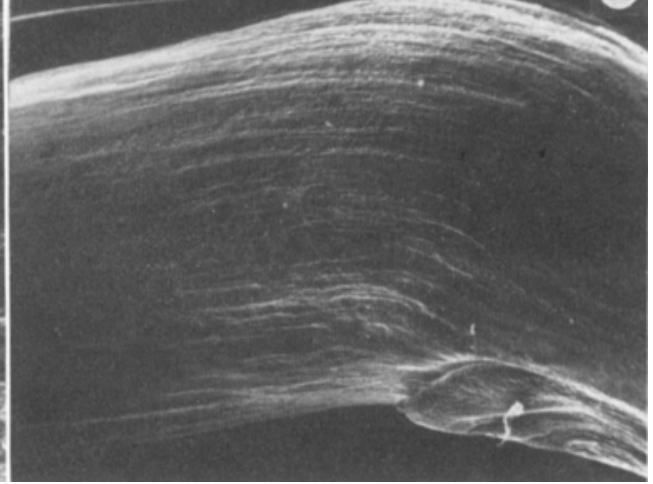
的

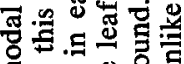
品

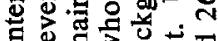

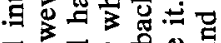

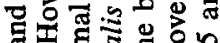
단

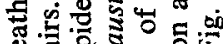

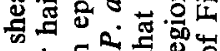

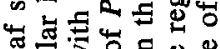

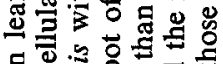

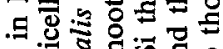

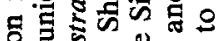

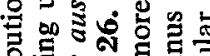

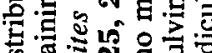

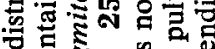

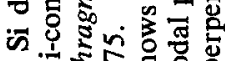

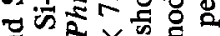

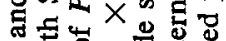

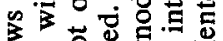

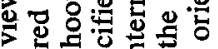

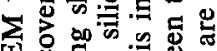

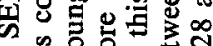
. के

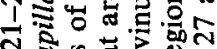
त 马्व

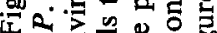

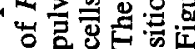


pulvini show very low levels of lignification in all plants examined. Figure 29 shows a longitudinal section of Hordeum distichon treated with pararosaniline- $\mathrm{HCl}$ to localize lignin. As can be seen, the pulvinus of the leaf sheath is free of lignin except for the xylem. Only annular and helical vessel elements are found in this region. In contrast, the xylem above and below the pulvinus region consists also of reticulate and pitted vessel elements. Prominent bundle caps are found in both regions (Fig. 29). In the sheath pulvinus region, the bundle cap cells (Fig. 2,4 ) are completely unlignified, but they readily stain with ruthenium red and show a positive reaction with hydroxylamine-Fe chloride reagent. Because of the presence of large quantities of pectin and structural resemblance to collenchyma cells (Dayanandan et al., 1976), we have called these cells collenchymatous. Immediately above and below the pulvinus region, the bundle cap cells are lignified and appear as typical lignified fibers (Fig. 29). Figure 30 shows the same section as in Fig. 29 but viewed between crossed polarizers. The collenchymatous bundle cap is strongly birefringent, and the orientation of cellulose microfibrils seems to be predominantly parallel to the length of the cells (Dayanandan et al., 1976). Panicoid grasses, such as corn (Zea mays), millet (Panicum miliaceum), and barnyard grass (Echinochloa crusgalli) possess both leaf sheath pulvini and internodal pulvini (Fig. 31; Table 1). In each of these cases, both the pulvini are completely devoid of lignification except for the $x y-$ lem elements (Fig. 32). Again, the xylem elements in these pulvinar regions are composed only of annular and helical elements (Fig. 42). The regions immediately above and below the pulvini have reticulate and pitted elements. Figures 33 and 34 represent two successive sections taken through the leaf sheath pulvinus and the internodal pulvinus regions of Panicum capillare. While the prominent bundle caps of the leaf sheath pulvinar region are not lignified (Fig. 33), the internodal bundle caps below the pulvinar region are lignified. The section shown in Fig. 34, taken at a slightly higher level, is through the internodal pulvinus where the bundle cap cells are unlignified. The bundle cap cells of the leaf sheath, on the other hand, are heavily lignified and assume a more peripheral position here. This clearly indicates that the internodal pulvinus is at a higher level than that of the leaf sheath pulvinus (Fig. 32). This is also the case in Zea mays, Phragmites australis, and Echinochloa crusgalli (Fig. 31).

Non-lignified, but pectin-rich collenchymatous cells comprising the bundle cap were found in all the leaf sheath pulvini of the more than 20 grasses examined. They were also found in every one of the nine grasses examined which possess internodal pulvini (Table 1). The pattern of distri- bution of the bundle caps and the associated vascular tissues in leaf sheath pulvini and internodal pulvini are shown in Fig. 35-42. About 30\% of the volume of leaf sheath pulvini in all grasses examined is occupied by pectin-rich collenchymatous cells. In cross sections of leaf sheath pulvini, the vascular bundles are distributed in a ring (Fig. 35, 37, 39). In Avena sativa and Zea mays, as in most other grasses, smaller bundles alternate with larger ones (Fig. 35, 37). Altogether, there are about 30 vascular bundles in Avena sativa, 40 in Panicum capillare, and 130 in Zea mays.

The distribution of vascular bundles in the internodal pulvini of Zea mays and Panicum capillare is illustrated in Fig. 36, 38, and 40. While the distribution in Zea mays seems to be scattered (Fig. 36), $P$. capillare shows 3-4 rings of vascular bundles (Fig. 33, 34, 38). The outermost ring of vascular bundles is embedded in a band of collenchymatous cells; the band is 200 to 250 $\mu \mathrm{m}$ in width and consists of 15-20 cell layers (Fig. 40). Such a broad band of collenchymatous cells is lacking in Zea mays (Fig. 36). Unlike Zea mays, the central portions of the $P$. capillare internodal pulvini are devoid of vascular bundles (Fig. 33, 34).

Statoliths and statocytes-Both the leaf sheath pulvini and internodal pulvini of all grasses examined possess starch statoliths. The distribution of starch statoliths after gravity stimulation, and the general pattern of statocyte distribution in Avena sativa, Zea mays, and Panicum capillare is shown in Fig. 35-43. In the leaf sheath pulvini, the statocytes are distributed adjacent to the vascular bundles, but they never completely encircle the entire bundle cap (Fig. 35, 39).

Most of the starch statolith-containing cells and some of the neighboring cells in the leaf sheath pulvinus of Avena sativa and Triticum aestivum also possess crystals of calcium oxalate, one per cell. These crystals were also found to sediment toward the gravitational field, just like the starch statoliths. Similar bodies were described by Prankerd (1920) as crystal statoliths in wheat.

Response to gravitational stimulation-While we have observed the geotropic bending response to gravitational stimulation in shoots of all of the grasses listed in Table 1 , we have studied this response in greatest detail in Avena sativa. When a shoot of Avena (contains only a sheath pulvinus) is held down horizontally by the stem region, a negative geotropic response occurs within $30-50 \mathrm{~min}$. The bending occurs during the first $24 \mathrm{~h}$ at a rate of $2^{\circ} \mathrm{h}^{-1}$. Thereafter, the rate is slowed down and the segment continues to bend until it reaches $90^{\circ}$. The initiation of the bending reaction is preceded by the sedimentation of starch statoliths, which complete their descent 


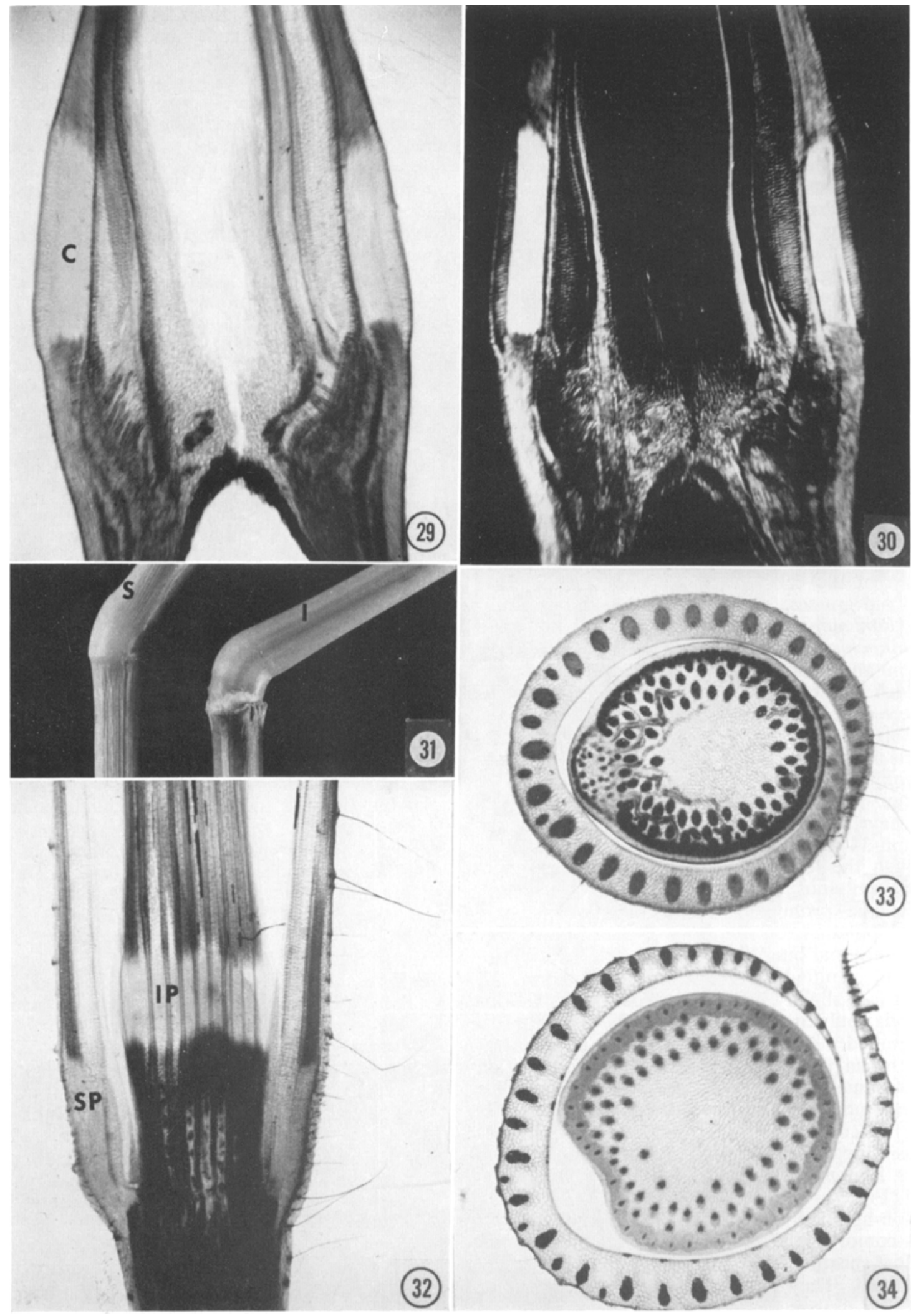


within 10-15 min after horizontal placement. The lower side of the pulvinus grows only by cell elongation. By reversing the segments after this response has occurred, the previously unstimulated upper side can be made to respond and elongate (Dayanandan et al., 1976). Along with the parenchyma and epidermal cells, the collenchymatous cells and the annular and helical vessel elements also elongate. The difference in length and structure between unelongated and elongated collenchymatous cells is shown in Fig. 2-4. Elongated cells become thinner in certain regions and assume a characteristic shape as seen between crossed polarizers (Fig. 2-4). Such a pattern of elongation was observed in the leaf sheath pulvini and in the internodal pulvini of more than 15 grasses examined.

In Avena sativa, Hordeum vulgare, Triticum aestivum, Secale cereale, and Phragmites australis, the growth of the lower side of the leaf sheath pulvini is solely due to cell elongation. Brandes and McGuire (1951) found that in three species of Saccharum and in one variety of Sorghum, the internodal pulvini responded to gravitational stimulation through cell elongation only. However, they also found, at least in one variety of sugarcane, that cell division did contribute to geotropic bending. Whether cell division activity in the gravity-sensitive regions is age-dependent and how many grasses show mitoses during geotropic bending is not known.

DisCUSSION-Hackel (1890) described all grasses except Molinia as possessing leaf sheath pulvini. Brown, Pratt, and Mobley (1959) investigated a total of 136 grasses and concluded that the members of the subfamily Festucoideae, on the one hand, possessed no internodal pulvini but did have highly specialized leaf sheath pulvini. Members of the Panicoideae, on the other hand, were said to possess fairly well-developed internodal pulvini but poorly-developed or no leaf sheath pulvini. We find this to be generally true in our detailed investigation of the 23 species listed in Table 1 . However, caution is necessary in accepting the data of Brown et al. (1959) regarding individual plants. For example, they state [following the description of Arber (1934)] that Phragmites australis does not possess a leaf sheath pulvinus. We find that it not only possesses a leaf sheath pulvinus, but also, that it exhibits the typical attributes of one, such as unlignified collenchymatous cells that elongate and functional statoliths. In the future, the presence of a gravity-sensitive region should be identified with the help of the following criteria: anatomical and morphological specialization, presence of statoliths, and cells that elongate in response to a gravitational stimulus.

Based on our limited study of about 25 different species of grasses, the following generalizations can be made about the gravity sensitive regions. They preferentially exclude Si from most of their epidermal cells during development, at maturity, and even after geotropic bending. They are characterized by the lack of lignified cells (except the vascular tissue) and the possession of annular or helical xylem elements. Pectin-rich collenchymatous cells are found in the bundle caps, and they elongate by a unique stretching pattern as seen between crossed polarizers. Low levels of silica and lignin and the presence of annular or helical xylem elements all have adaptive significance-they make the pulvini less rigid and allow them to elongate readily. All gravitysensitive regions also possess starch grains that act as statoliths. Whether calcium oxalate crystals that are found in Avena sativa and Triticum aestivum also act as statoliths, and if such crystals are found in other grasses, is not known.

We have found (Dayanandan et al., 1976) that the pulvini are sensitive to auxin and that the geotropic response is completely suppressed by auxin transport inhibitors. We have also found that symmetrically applied ${ }^{14} \mathrm{C}$-IAA preferentially accumulates on the lower side of leaf sheath pulvini

$\leftarrow$

Fig. 29-34. Anatomical features of leaf sheath and internodal pulvini in Hordeum distichon, Echinochloa crusgalli, and Panicum capillare. 29. Longitudinal section of $H$. distichon treated with pararosaniline-HCl for lignin and counter-stained with fast green. The collenchymatous (C) bundle caps are free from lignin except for the xylem. The internode does not possess a pulvinus. $\times 23$. 30. Same section as in Fig. 29 , but viewed between crossed polarizers. The long axis of the bundle cap was placed at $45^{\circ}$ to the axis of the polarizer. $\times 23$. 31. Geotropically stimulated shoots of $E$. crusgalli showing the left sheath pulvinus at left, and the internodal pulvinus in a shoot whose leaf sheath has been removed. S, leaf sheath; $I$, internode. The internodal pulvinus is at a higher level compared with the leaf sheath pulvinus; but both pulvini respond to gravitational stimulation. $\times 15$. 32 . A longitudinal section (not quite median) of a shoot of $P$. capillare treated with pararosaniline- $\mathrm{HCl}$ and fast green. Leaf sheath pulvinus (SP) and internodal pulvinus (IP) are free from lignin except in the vascular tissue. $\times 11.33, \mathbf{3 4}$. Cross sections of $P$. capillare through two different levels at the base of the internode. At a lower level (Fig. 33), the collenchymatous bundle caps of the leaf sheath pulvinus are prominent and are free from lignin. The internode at this level is heavily lignified. Axillary bud is also seen in this cross section. At a higher level (Fig. 34), the bundle caps of the leaf sheath assume a peripheral position and are lignified. The section here passes through the internodal pulvinus which shows lignification only in the vascular tissue. Both sections were treated with pararosaniline$\mathrm{HCl}$ and counter-stained with fast green. Both $\times 11$. 

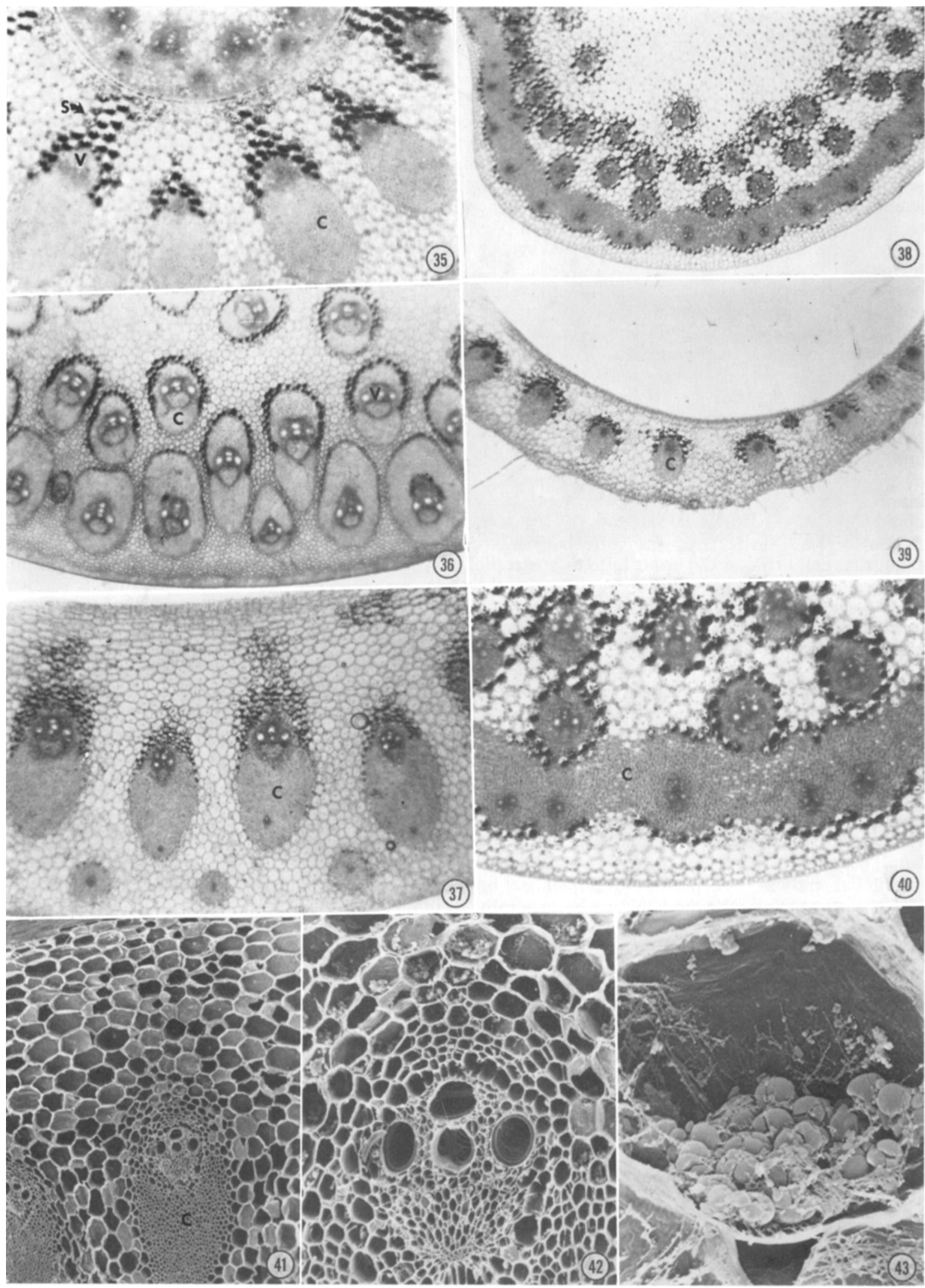
in horizontally placed shoots. Further investigation of the geotropic response of the sheath internodal pulvini is necessary to understand and to be able to regulate this response in economically important grasses.

Several interesting questions emanate from the present study of gravity-sensitive regions in grass shoots: Why in some grasses are there two different locations for the geotropic response in the shoot, one in the leaf sheath and one in the internode? What taxonomic relationship, if any, does their distribution have to the different subfamilies of grasses? How is the internodal pulvinar region related to the basal internode intercalary meristem in its developmental history? How is $\mathrm{Si}$, which has to pass through this region to higher levels, excluded from the epidermal system? What prevents the deposition of lignin and the accumulation of pectin in the collenchymatous cells of the bundle caps? And what controls the peculiar pattern of cell elongation observed in the collenchymatous cells?

\section{LITERATURE CITED}

Arber, A. 1934. The Gramineae. The University Press, Cambrige.

Arslan, N., and T. A. Bennet-Clark. 1960. Geotropic behaviour of grass nodes. J. Exp. Bot. 11: $1-12$.

Artschwager, E. 1940. Morphology of the vegetative organs of sugarcane. J. Agric. Res. 60: 503-550. 1948. Anatomy and morphology of the vegetative organs of Sorghum vulgare. U.S. Dept. Agric. Tech. Bull. 957.

Brandes, E. W., AND R. C. MCGuire. 1951. Auxinthermal relations in cell growth and geotropic reaction of sugarcane. Amer. J. Bot. 3: 381-389.

BRIDGES, I. G., AND M. B. WILKINS. 1973. Growth initiation in the geotropic response of the wheat node. Planta (Berl.) 112: 191-200.
Brown, W. V., W. F. Harris, and J. D. Graham. 1959. Grass morphology and systematics. I. The internode. Southwest. Nat. 4: 115-125.

- , G. A. Pratt, and H. M. Mobley. 1959. Grass morphology and systematics. II. The nodal pulvinus. Southwest. Nat. 4: 126-130.

Dayanandan, P., F. V. Hebard, and P. B. Kaufman. 1976. Cell elongation in the grass pulvinus in response to geotropic stimulation by auxin application. Planta (Berl.) 131: 245-252.

ElfViNG, F. 1883-1884. Ueber das Verhalten der Grasknoten am Klinostat. Ofversigt af Finska Vetenskaps-Societens Förhandlingar, Helsingfors, Vol. 25, p. 107-111.

Gould, F. W. 1968. Grass systematics. McGraw-Hill, New York.

HACKEL, E. 1890. The true grasses. Henry Holt and Co., New York.

JENSEN, W. A. 1962. Botanical histochemistry. W. H. Freeman, San Francisco-London.

Kaufman, P. B., W. C. Bigelow, L. B. Petering, and F. B. Drogosz. 1969. Silica in developing epidermal cells of Avena internodes: electron microprobe analysis. Science 166: 1015-1017.

LeHMAN, E. 1906. Zur Kenntnis der Grassgelenke. Dtsch. Bot. Gesell. Ber. 24: 185-189.

MAEDA, E. 1958. The effects of growth regulators on the geotropism of the leaf sheath basal region in wheat. J. Exp. Bot. 9: 343-349.

Montemartini, L. 1900. Sopra I Nodi Delle Graminacee. Malpighia XIV: 271-274.

Osborne, D. J. 1974. Auxin, ethylene and the growth of cells, p. 645-654. In R. L. Bieleski, A. R. Ferguson, and M. M. Cresswell [ed.], Mechanisms of regulation of plant growth. Bulletin 12, The Royal Society of New Zealand, Wellington.

Prankerd, T. L. 1920. Statocytes of the wheat haulm. Bot. Gaz. 70: 148-152.

SACHS, J. 1872. Längenwachsthum der Ober- und Unterseite horizontal-gelegter sich aufwärts krümmender Sprosse. II. Versuche mit Grashalmen. Arbeit. d. Bot. Inst., Wurzb. Vol. 1, Heft II, p. 195209.

$\leftarrow$

Fig. 35-43. Anatomical features of leaf sheath and internodal pulvini of selected grasses as seen in cross sections. All preparations are from the lower halves of pulvini that have been geotropically stimulated for $1 \mathrm{~h}$. C, collenchymatous bundle cap; V, vascular tissue; $\mathrm{S}$, statocytes. 35. Leaf sheath pulvinus surrounding the internode in $A$ vena sativa. The statoliths have sedimented towards the gravitational field due to geotropic stimulation. A few statocytes are also seen in the internode. Free-hand section stained with $I_{2} \mathrm{KI}$. $\times 100$. 36. Internodal pulvinus of $Z e a$ mays. Vascular bundles are completely surrounded by collenchymatous cells, which in turn, are partially or completely surrounded by 1-2 layers of statocytes. Collenchymatous cells are also found in the hypodermis. Free-hand section stained with $I_{2}$ KI. $\times 50$. 37. Vascular bundles, collenchymatous cells, and statocytes of a leaf sheath pulvinus of Zea mays. $\times 36$. 38. Free-hand section of an internodal pulvinus of Panicum capillare stained with $I_{2} K I$. $\times 28$. 39. Leaf sheath pulvinus of $P$. capillare. Outer epidermis of the pulvinus has epidermal hairs. $\times 28.40$. An enlarged view of a portion of the pulvinus in Fig. 38. Statocytes of 1-2 layers surround the collenchymatous bundle cap. Outermost bundle caps have coalesced to form a continuous band of collenchymatous cells. There is no hypodermal collenchymatous tissue in this plant. $\times 58.41,42$. SEM views of leaf sheath pulvinus of Zea mays. Fig. 41. $\times 60$. Fig. 42. $\times 200$. 43. SEM view of a single statocyte from the internodal pulvinus of Zea mays. Statoliths, that have sedimented towards the graviational field are amyloplasts, each with 4-6 grains. Precipitation of the protoplasm by FAA-fixation has resulted in the presence of many strands. $\times 1,550$. 